\title{
The Possibility of Applying Regional Specificity in the Development of Tourist Routes of Excursions (On the Example of the Theme "A. Dumas (Senior) About the Caucasus")
}

\author{
Fatimet Khuako \\ Federal state budgetary educational institution of higher \\ education \\ Maikop state technological university \\ Maikop, Russian Federation
}

\author{
Anzhelika Kumpilova \\ Federal state budgetary educational institution of higher \\ education \\ Maikop state technological university \\ Maikop, Russian Federation \\ andju@mail.ru
}

\begin{abstract}
This article is devoted to the consideration of the possibilities of using the literary theme in the formation of the excursion material. Ideas of regional and economic tourism come up today in scientific discussions often, which is illustrated by the facts cited in this article. However, the possibility of using literature for the purpose has not been researched sufficiently. Starting with the theme of tourism in modern science, the authors of the work move to the publicist prose of the French novelist. The journey of the writer of the XIX century: Alexander Dumas (senior) is clearly embodied in his publication "Caucasus", which analyzes the work. Comparing the facts cited by the writer with the historical information of $F$. Khuako, A. Kumpilova recommendations for the use offer such material in the local excursions. In that role in the article presents so: the agreement and the according of excursion roads with the ways, on which A. Duma is going in the Caucasus and, accordingly, the using of A. Duma's remarks about the real visual objects (land, people, brands, folklore). The use of the ethno- esthetic material given by us is able to interest anyone coming to the Caucasus with the opportunity to feel feelings similar to the impressions of the great French author. This kind of innovation can be really reflected in the business strategy for the North Caucasus region, which is built taking into account the ethno-regional specifics that the authors of the article focus on.
\end{abstract}

Keywords: tourism, eco-tour, excursion, the Caucasus, Alexandr Duma, trip, local culture

\section{INTRODUCTION}

The unbroken formation and constant progressing of tourism industry on the Russia's territory in the modern reality is working as the strong element in the whole cycle of socialpolitic and financial problems. Moreover that can be use as on the federal, as on the regional levels. For example, the continuation and the possible perfection of provincial economical attractiveness on Russia's and than - on planet's land is possess the potential of perception's improvement of country on the global economical ring. If we are directly turning to RF- regions: precisely on the North Caucasian space may to say about fact - tourism can to work as one of the prioritize sphere of population's being busy and of possible profitableness. This, of course, is caused by territorial and geographical specificity of region, its land shaft and ethnographical resources. That is way so fact it is impossible to forget in the time of long programs of economical (service) progress.

Today's possibility of tourism branch as the potential effective industrial production does not go out from the attention of science: «Tourism as an interdisciplinary economic and social activity can connect all the economic factors of a region that is, strengthen cross-border geographical areas. Due to the international dimension and travel destinations are becoming an important factor of national and regional connectivity, which emphasizes the need for a special type of regionalization». Yet after break-up of soviet country, when were knock off the obstacles and frontiers, the RF- tourism sphere got very useful instruments for the organization of movement between countries - own and neighbor. Moreover often and extensive are discussing precisely the possibility of tourism's modernization $[2,3,4,5$, $6,7,8]$. But the most activity on the global science field in conformity with our object the Caucasus colleagues (Armenia, Azerbaijan), and, especially, - Georgia [9, 10, 11, $12,13,14]$. And as most active on the post- soviet land may to call the excursion and the sea- close rest, which were usual for soviet people. 
However, «there is no a single concept to advertise the eco-tourist potential of the country, there is no a single logo, colors or principal and necessary advertising attributes of ecotourism developed so far (the tourism generally is not concerned, as the advertisement attributes for Georgia are developed)». So far as the primary part of excursions traditionally must to base on the certain, real being objects, the main method in it's going is the unison of visual and word. The composition of excursion's text more often may to include the whole theme's range of supplementary components. They, in there roles, must to be demonstrate by excursion's material, to submitting of main theme. Moreover the seriously argument in the building of excursion may to call it's structure. Here may to be comprise so elements, which can to translate the mean of central theme. They must to do it in the time- limit, what defines by the weighty of such point for the whole theme. As is establishing today in the classification of conception, pick out three central lines, which can to influence on the social life: economical, social and humanitarian. However the humanitarian direction is very nipping, dominating is economical. But none economical creative not to be in the isolation from the word. That is why we in our work are doing the accent on the that sphere. That is why to talk about successfully humanitarian direction is problematically, what is causes the actuality of our researching.

\section{METHODS}

The target of the excursion mainly being the demonstration to clients a historical, a cultural and a architecture objects. The guide's story in this case directed on those target. Thus the marking problem is the information- analytical or the demonstration opening of the established theme. And that is why in the role of lively illustration material in the trip on Caucasus's way we are offer to active use the color paint, what did the celebrity France Romanist, who visited here in his time. Alexandr Duma (elder) in 1858 - 1859 was crossed the Russia on tour with the accompaniment of his (fellow-) countryman painter J. Muane. And three from the ten trip's months was continued him precisely on the North Caucasus. The scheme of its trip, as noted in the chronic of Dagestan historic XIX c. Kh. Donog, that: from the Black See port Poti across Kutaisi in Tiflis (Tbilisi), then - in the Baku, then - in the North Caucasus points. Later as the conditional total of emotions, which was summed during the trip, did the printing of powerful book "Caucasus" in the three volumes (Paris, 1859, April). Then, two years later, very stronger shorten "Caucasus" was published on the russian language (1861). In the our time (1988) in the publish house "Merani" (Tbilisi, Georgia) printed so book, which illustrated by paints from painters (G. Gagarin, T. Gorshelt, J. Muane) and from fotoarchives. Such publication its redactor T. Buachidze calls "most full in our country". That is why precisely that book we may to use in the process of excursion's activate by the interesting for tourist information. And that is why the analyze, translate and comparison the material, to having here, with the going to tourist excursion, we reckoned as adequate methods in the research.

\section{RESULTS}

On the background of a great romanist's activity in the Caucasus land we'll came back to excursion's possibility of these territories. Moreover, as witnesses the today science, the hotel business on the Caucasus is in the strong decline: «During soviet times, the Kazbegi region featured several large- scale soviet hotels and tourism was a major business in the re $\neg$ gion. It had become a mountaineering center and was well-known for its nature and mountain sports activities. However, the facilities from that time are now run-down and due to uncontrolled tourism, the landscape and ecosystems suffered damages» . And the tourist, coming here for unknown for him information, may to work as the seriously depositor to this land. But the potential here, as known, worthy: «As the Caucasus coastal zone was under the great anthropogenic stress historically and recently the conditions became critical and the situation became extremely complicated in natural environment, therefore, extreme ecological situation have been occurred in many places». The demonstration of going or ever went processes (geographical and housel) is sees as the point, which has a primary place in the excursion. Exactly sorting of present objects, theirs number and structure, the logic of agreement may to determine the excursion's (and then, - economical) effect. We are daring to suppose in this case the possible effective conformity of excursion's lines with the way A. Duma on Caucasus, because that way- criteria has the potential of optimally present for excursion theme. Such potentially effective route is successful in the intention of its creators to guarantee the demonstrating canvas, which surrounds so theme. Those canvas will attract in next time the visitors into that lands, what will give the economical profit.

To tripping in the Caucasus lands the France writer admires of the most from he sees. And animated, and inanimate paints predetermines his joyful revelations and information upcasts in the economical effect. A lot of geographical details in the text often accompanies by the narrations of regionally legends and tales. But carrying to reader's attention the whole range of ancients tales, he sends by himself. Calling himself to leave the myths, he recommends the turning to history, what doing then on the ten own papers. The author's review of the Caucasus's chronology doing with detailing the rang of facts the past seizures and attempts of enslaves. The unique, what frankly worries and angers him in the paints it is the radicalism, the cruelty and the indifference. For him is the joy to talk about the pure-minded and the generously, the warmth and the kindness. He is point-blank compassions to the unfair pinching. For example, to talking about the time of Ekaterina II, A. Duma specifies: "Since that moment the Russia going with Caucasus towns almost as the owner". But he ends this review, to belonging yet to the son of Ekaterina, potentially active. Here the last lines of initiative works in the role of beginning for another chapters: in the moment of coming out from the power a dead leader in the branch of one lezgin's tribe was born "on the light the child" with name Shamil, that is "tomorrow imam". Precisely that character became the most dynamic hero then, in the post chapter. A. Duma constantly mentions him, cites and even talks about his acts (and battle, and human) with a respect. So, for example, the writer sure 
that the mountaineers like to smoke. But here in that moment - the fact: "Shamil directed: no more smokes. <..> And really, all stopped to smoked". Further sometimes in the talking there are: the resource, the resolution and the courage of Shamil. Those fact with cigarette may be use in the mainly for clients antismoke reclaim.

The mainly using the generally accepted in the prerevolution world out-name "cherkes", the author don't forget to explain the own-nation name "adyge". To translating the word "ada" as "island" (is so in the theory of oring), he here illustrates this info by the another parallel: "Ad and Adam, what means the man, are different each from other only with two letters - so gloomy etymology!" . Or painting him the house, which carries the defence of cherkeses, associates for him with the traditional comparison - fortress. That may to be use in the story of excursion's guide as the base for insertions about building technologies, which use in the different regions of country. And the strong mountain in those war defenses helps them, as wanting "to come in the line of russian enemies" and longing with "the roar and the crack for carry a third part of battalion away".

And on the so color comparisons, intellectually remarks is building the paint of all text. The often detail here searches the tone in the strong informational resource, which gives to the dry detail the lively and figurative. It's may to be fluency for the potential client. Moreover here may to see currently statistic: the most often in the using by author comparisons we confidently note the ornithological instruments. In the painting of whole range mountain objects, sometimes a little similar to each other, author likes the comparison precisely with the birds and the nature of theirs life. For example, the village here, which takes the prince with his favorite women, is same as "the eagle's nest, building on the scale". And the cherkeses, which using the war tactic "flying to mountains", doing it "as the flock of kites". So the expressive tendency we may try to explain by the world literature step: is the interest of creator to the flying lively object. They can to give for tourist his own, very person for him associations, which were typical for his motherland. And then those client yet different, very more subjective (and that is why potentially profitable) will understand the land, which laying in front him.

In the modern for A. Duma esthetic the bird's figure worked in the role of the accompanying to people the alive creature, moreover - the leader in prevalence. Functionally that figure was very saturate in the artistic lines, because personified the lot of character's traits, such as: 1) positive (the independence, the quickness, the marksmanship, the skill to agree, the ear for music and the talent); 2) but sometimes, negative (the carnivorous, the exactingness and the lightness). That is the hole cycle of person trait, about what is deciding and tourist client. In that time, in conformity with the clear nature diversity, those phrases and decisions of global literature's master may to be use in the excursion's account. To accompanying the geographic points (which are the points for birds living) with the help of the A. Duma's word, it is really to do it by his concrete cites. So tactic will promise the tourist in the true of information. The analogical methodic has to possibility not only in conformity with the lively, but with the geographic brands of Caucasus. And the permanent toponymy's remarks are surprise and also gratefully strike of that intellectual knowledge, which has the france romanist A. Duma. The thankful excursion's client will take here for himself a lot of interest materials about the territory. For example, in the first part (which has a global info about Caucasus) yet, the author, to going in the some geographic point, often accompanies the talking by the translating of its name. Moreover, to scheming the addressor more and more, he turns also to the history, to the using versions of this land's born. For example, in the continuer of acquaintance with the river Kuban we are recognized about the different toponymy's variants of that object (Kuman), what may to say for interesting tourist. The Caucasus's etymology is making here by the reducing the whole range of legends and myths, also theirs heroes (but in dominate, - the Greece (Saturn, Jupiter, Prometey)). And moreover - the expressive file of his own (author's) suppositions about the objects. Or author's using the Derbent and Daryal canyons in the Georgia, and also connected with that the national tales about the old family Bagration, the kings Darya and Aleksandr, about theirs conquests between the Azov and Kaspiy Seas. And another facts. Such type of enchantment will always each client, because the mystic and the magic are interest for people in the each civilization.

\section{DISCUSSION}

In the result (as thinks the author of Introduction in the book "Caucasus" M. Buyanov), that work is "delights by not only the esthetic qualities, but so by the objective materials, by the punctually paint: to be a inventor A. Duma, in the first place, was the observant man and the great workman". The client in that moment revives of the such logical and yet with the author lively deciding the hypotheses, which gives writer, and also builds the own versions as an answers. But if that logical arguments moreover by the definite translate of Koran, it becomes more convincing. For example, only in the Koran (the holy, as decided author, for all musclemen) "Aleksandr Macedonian calls as Zul-Karnain, what means "has a two horns" . And the name "Zulkarine" is very useful in the adyge society today. The such facts may to be effective use in the create of itinerary the directly religion tourism. About than tourism type also often talking today the science management of Russia: «Permanently growing interest in religious tourism can make it an important factor of ensuring social stability and interfaith dialogue in the society. In the given article the author aims to reveal the socio- cultural nature of religious tourism and analyze its unique opportunities in weakening the reasons and conditions of social tension». Or surprised the france guest by the places of leaving people, when men don't always might to do more culturally. Here, in the first place, he (as another, who came in the Russia many centuries) surprises by the regional roads, which are known for hole planet and, for example, - for coming here tourist. It shocks him often of theirs neglect. So, for example, to painting his way- stage before and after Kizlyar, he is doing it precisely on the information about the road cover's quality. And, to leading the tourists on that mountain's ways, may to remember the author's decides about it. He compares the different lands: the smoothness and the uprightness - after Astrakhan; the twisting and the hilly - after Kizlyar. On the base of so materials the 
tripper, who really seen the world, is very expressive again: the european coachman will stop his work, but regional master is more cruel, he continue the way and doing it stronger with the steepness. The artistic word of writer about this lands very polysemantic: "The man has to have the iron nerves, and the carriage - the iron mechanism for stand normal in the such tracking".

\section{CONCLUSION}

To recollecting the A. Duma's remarks in the corresponding lands, the tour guide may to do analogy with theirs conditions today. That will interest the tourist by so logical "brilliant" (brands), which demonstrates on its place. So, for example, may to remember the Caucasus drinks, which staying as popular today: «Today Borjomi is logistically strengthened with Borjomi water production plant, mineral springs and infrastructure which im $\neg$ proves recreational, cultural and touristic segment. The number of tourists increases every year, what clearly indicates the prospects for the new development of Borjomi spa and balneology sector». And the details of house's live here also may be use. For example, agrarian technologies and theirs modern in the counterpoise to cheap soviet gas: «Nowadays agricultural production in the Kazbegi dis $\neg$ trict mainly comprises potato growing and cattle production for meat and dairy products». Moreover - in the rural tourism: «Despite all the attractiveness of tourist product, it is difficult for Georgia to strengthen its position at the global market with mass tourism, accordingly tourism development policy should focus on the promotion of small tourism business where rural (farmers', family) tourism with its good prospects in Georgia should play an important role». In that time the meeting of tourists with the theme may by traditionally tactic: "Informing the educational establishments, tour-operators, media and other organizations and expanding communication channels with wide society is also necessary»). Here we are certainly agreeing with $\mathbf{M}$. Buyanov, who fair calls as one of the professional lines of A. Duma the absence of indifference: «Duma was intoxicated by the Caucasus, not by the wine». In the whole so, the drugging, but don't agree and the gladdening intoxication may to be understand so. In fact it is healthy creator's interest of intellectually world master, who fires of materials in his notebooks and who is rich of the images in own fancy. That potential substation may be the effective using on the history and the culture saturated land, what is expressive seen in the analyzing work A. Duma "Caucasus". As known, tourists come to unexplored for them areas, following the desire to have fun, but at the same time to learn something new. Such healthy curiosity can be effectively applied in the course of excursion developments, which we are talking about in our research. The use of the ethno- esthetic material given by us is able to interest anyone coming to the Caucasus with the opportunity to feel feelings similar to the impressions of the great French author. And such innovations can be really reflected in the business strategy of the North Caucasus region in combination with the ethno- regional specifics, which we used above.

\section{ACKNOWLEDGMENTS}

Clouse to the theme science lecture ("The outer (A. Duma) and the inner (T. Kerashev) romanistic in the looking of Caucasus's lands and people") was been 15.11.2017 on the Republic science conference "The phenomena of creator individual of T. Kerashev in the global Russia's culture" (Maykop, AGU). The article's publication on the so theme was later: Khuako, F.N. "The outer (A. Duma) and the inner (T. Kerashev) romanistic under the impression from Caucasus", ESU, vol. 6 (63), pp. 58-61, 2019 (DOI: 10.31618/ESU.2413-9335.2019.7.63.190).

\section{REFERENCES}

[1] M. Milenkovic, "Ecoregionalism - factor cross-border cooperation and tourism development", Procedia-Social and Behavioral Science, vol. 44, pp. 236-240, 2012.

[2] A. Bozkir, E. Sezer, "Predicting food demand in food courts by decision tree approaches", Procedia Computer Science, vol. 3, pp. 759-763, 2011.

[3] F. Khalili, E. Safarov and Sh. Bayramova, "A glimpse of YOCOCU future. Cultural Heritage in Azerbaijan via MIRAS Social Organization and Agsu Archaeological Expedition”, Procedia Chemistry, vol. 8, pp. 337-347, 2013.

[4] M. Giusti, "The web as a channel to connect the current and traditional cultural consumptions", Procedia-Social and Behavioral Science, vol. 103, pp. 1210-2019, 2013 [13th International Education Technology Conference].

[5] T. Akhmetzianov, V. Kosachev, "Forecasting Of Innovative Activity Dynamics Using Industry Competition Indicators Analysis (Evidence From Food Industry of Russia)", Procedia Economics and Finance, vol. 39, pp. 746-752, 2016.

[6] T. Mantayeva, A. Kuzeubay, F. Zhumazhanova, M. Komekova, Zh. Moldabekov and T. Gabitov, "The possibilities of inheritance of Great Silk Way to prosper cultural personality", Procedia-Social and Behavioral Science, vol. 197, pp. 537-542, 2015.

[7] U. Batsaikhan, M. Dabrowski, "Central Asia - twenty-five years after the breakup of the USSR", Russian Journal of Economics, vol. 3, pp. 296-320, 2017.

[8] Y. Xiao, C. Benoit Norris, M. Lenzen, G. Norris and J. Murray, "How Social Footprints of Nations Can Assist in Achieving the Sustainable Development Goals", Ecological Economics, vol. 135, pp. 55-65, 2017.

[9] E. Tsereteli, R. Goejishvili, N. Bolashvili, V. Geladze and G. Gaprindashvili, "Crisis intensications of geoecological situation of the Caucasus Black Sea coast and the strategy of risk reduction", Procedia Social and Behavioral Science, vol. 19, pp. 7009-715, 2011.

[10] E. Vardanyan, "The indicators characterizing alterations of Tavush region natural landscapes", Annals of agrarian science, vol. 14, pp. 273277, 2016.

[11] J. Heiny, G. Mamniashvili and I. Leonhaeuser, "The socioeconomic situation of private household in the Kazbegi region - First insights based on quantitative data", Annals of agrarian science, vol. 15, pp. 31 39, 2017.

[12] N. Paresashvili, "Major tasks of ecotourism management in Georgia", Procedia-Social and Behavioral Science, vol. 156, pp. 170-173, 2014.

[13] O. Paresishvili, L. Kvaratskhelia, V. Mirzaeva, "Rural tourism as a promising trend of small business in Georgia: topicality, capabilities, peculiarities”, Annals of Agrarian Science, vol. 15, pp. 344-348, 2017.

[14] Ts. Z. Basilashvili, "Reservoirs on the mountain rivers and their safety", Annals of Agrarian Science, vol. 14, pp. 61-63, 2016.

[15] N. Paresashvili, "Major tasks of ecotourism management in Georgia", Procedia-Social and Behavioral Science, vol. 156, pp. 170-173, 2014.

[16] A. Dumas, “The Caucasus". - Tbilisi: Merani, 1988 // http://anl.az/new/upload/File/berpa/berpa-15-file.pdf. 
[21] Kurmanalieva, Sh. Rysbekova, A. Duissenbayeva, I. Ismailov, "Religious tourism as a sociocultural phenomenon of the present "The unique sense today is a universal value tomorrow. This is the way religions are created and values are made", Procedia-Social and Behavioral Science, vol. 143, pp. 958-963, 2014. based on quantitative data", Annals of agrarian science, vol. 15, pp. 3139, 2017.

[18] E. Tsereteli, R. Goejishvili, N. Bolashvili, V. Geladze and G Gaprindashvili, "Crisis intensications of geoecological situation of the Caucasus Black Sea coast and the strategy of risk reduction", Procedia Social and Behavioral Science, vol. 19, pp. 7009-715, 2011.

[19] A. Dumas, “The Caucasus". - Maykop: JSC Polygraph-SOUTH, 2015.

[20] M. Buyanov, Introduction // A. Dumas, "The Caucasus". - Tbilisi: Merani, 1988 // http://anl.az/new/upload/File/berpa/berpa-15-file.pdf.

[22] T. Khoshtaria, N. Chachava, "The planning of urban green areas and its protective importance in resort cities (case of Georgian resorts)", Annals of Agrarian Science, vol. 15, pp. 217-223, 2017.

[23] S. Huller, J. Heiny, I.-U. Leonhauser, "Linking agricultural food production and rural tourism in the Kazbegi district - A qualitative study", Annals of Agrarian Science, vol. 15, pp. 40-48, 2017. 